\title{
New era of heart failure therapy in pediatrics: Cardiac stem cell therapy on the start line
}

\author{
Shunji Sano, MD, PhD, Shuta Ishigami, MD, PhD, and Toshikazu Sano, MD, PhD
}

\footnotetext{
From the Department of Pediatric Cardiothoracic Surgery, University of California, San Francisco, San Francisco, Calif.

Received for publication March 29, 2018; revisions received May 14, 2019; accepted for publication May 15, 2019; available ahead of print June 24, 2019

Address for reprints: Shunji Sano, MD, PhD, Division of Pediatric Cardiothoracic Surgery, University of California, San Francisco, Pediatric CT Surgery, 550 16th St, Floor 5, San Francisco, CA 94143-0117 (E-mail: Shunji. sano@ucsf.edu).

J Thorac Cardiovasc Surg 2019;158:845-9

$0022-5223 / \$ 36.00$

Copyright $\odot 2019$ Published by Elsevier Inc. on behalf of The American Association for Thoracic Surgery https://doi.org/10.1016/j.jtcvs.2019.05.002
}

Over the past 2 decades, early diagnosis, improvements of preoperative care, and the evolution of catheter interventions and surgical procedures have led to notable progress in the early and long-term outlook for children with congenital heart diseases (CHDs). In particular, improved results have been realized in patients with single ventricular (SV) physiology, including hypoplastic left heart syndrome (HLHS). ${ }^{1}$ Greater than $90 \%$ of newborns with CHD, even those with most complex anomalies, survive the first year of life. Even though remarkable advances in treatments have been realized, our procedures for SV and HLHS are palliative rather than curative and often cause cardiac and noncardiac complications associated with significant mortality and morbidity in the long term. Actual 5-year survival of HLHS has ranged from $50 \%$ to $69 \%$, but current expectations are that approximately $70 \%$ of neonates with HLHS may reach adulthood. After the Fontan procedure for SV physiology, heart failure has been reported to develop during childhood in up to $10 \%$ to $20 \%$ of patients and reaches nearly $50 \%$ by adulthood. ${ }^{2}$ The most common cause of late complications in these SV physiology patients is heart failure. To achieve better long-term outcomes for children with SV physiology, preserving ventricular function is one of the most important determinant factor of prognosis. ${ }^{3}$ Therefore, anti-heart failure medical or interventional therapy for SV physiology is strongly desired.

\section{CARDIAC REGENERATION AND STEM CELL THERAPY}

For the past 2 decades, stem cell therapies have emerged as one of the most highly investigated treatments for cardiovascular disease. A majority of the preclinical and clinical research in stem cell therapy for heart disease has been focused on the recovery or regeneration of ischemic myocardium in adult patients. ${ }^{4}$ Less attention was paid to the patients with pediatric heart failure. Numerous clinical trials using various types of stem cells were conducted to heal injured myocardium in the adult. ${ }^{4}$ Somatic stem cells,

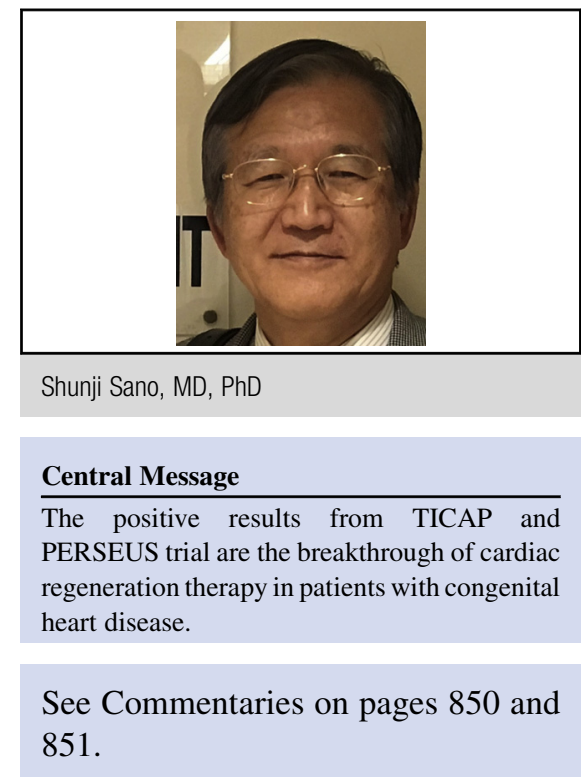

including cells derived from the heart, bone marrow, adipose tissue, and even circulating non-myocardial progenitors, are the major cell types that might give rise to cardiomyocytes, which in theory could be used in clinical trials. ${ }^{5}$ Several routes of delivery of stem cells, including intracoronary, intramyocardial, and intravenous, are applied to the heart. Recent systemic reviews and meta-analyses related to stem cell therapy for heart failure have revealed the benefit of cell therapies for cardiac function, exercise tolerance, and quality of life (QOL) in the adult population. ${ }^{4,6}$

In parallel with advances in the application of bone marrow-derived mesenchymal cells has been the intense investigation of the therapeutic potential of c-kit + resident cardiac progenitor cells (CPCs) and cardiosphere-derived cells (CDCs). C-kit + CPCs refer to a multipotent cell population expressing the tyrosine kinase receptor c-kit. They are thought to be a primary source for the generation of new myocardium in the setting of myocardial injury. ${ }^{7}$ CDCs, derived from the mesenchymal component of heart tissue, have been found to possess a multipotent ability. CDCs consist of a heterogeneous cell population and represent mesenchymal stem cell-like surface marker such as CD105 and CD29 expressions. However, no single definitive cell surface marker has been detected to identify this progenitor cell population. Unlike c-kit+ CPCs that are purified based on expression of c-kit, CDCs do not require cell sorting. 
The discovery of endogenous CPCs is one of the exciting new technologies in the field of cardiac regeneration, which has yielded much interest relating to their proliferative and differentiation potentials. Recent reports have demonstrated that compared with noncardiac stem cells, endogenous cardiac progenitor/stem cells have superior regenerative ability. During the past decade, several independent laboratories have shown that transplantation of endogenous CPCs improves ventricular function and enhances ventricular remodeling in an animal model of acute and chronic ischemic heart failure. CDCs have been shown to exert a greater functional benefit in experimental myocardial infarction (MI) with respect to their remarkable potential for myogenic differentiation, angiogenesis, and paracrine factor secretion compared with other cell types. On the basis of these results, the first-in-human phase I Food and Drug Administration-approved clinical trial using autologous c-kit + CPCs in patients with myocardial ischemia commenced in 2009 (Cardiac Stem Cell Infusion in Patients With Ischemic Cardiomyopathy [SCIPIO] trial). About 4 months after bypass surgery, c-kit $+\mathrm{CPC}-$ treated patients were administered c-kit + CPCs by intracoronary injection. Although the 2-year follow up has not been published yet, the interim and 1-year results of the SCIPIO trial are quite impressive. $^{8}$

The CADUCEUS (Cardiosphere-Derived Autologous Stem Cells to Reverse Ventricular Dysfunction and Autologous Cardiosphere-Derived Cells) trial demonstrated that the CDC-treated patients had no reported arrhythmias, tumor formation, MI, or other serious adverse cardiac events. Despite no improvements in cardiac function, there was significant reduction in scar mass, increased viable heart mass, regional contractility, and systolic wall thickening. ${ }^{9}$ Recently, like mesenchymal stem cells, the administration of allogeneic CDCs has been shown to be safe and had successfully promoted cardiac regeneration and improved cardiac function in animal models of MI. ${ }^{10,11}$ With these encouraging results, many clinical trials are being studied in adult patients with ischemia using allogeneic CDCs rather than the autologous cells.

Neonatal CPCs have been shown to process superior therapeutic potency with respect to adult CPCs in a rat MI model. Neonatal CPC administration was associated with preservation of left ventricular ejection fraction at 7 days and 28 days postinjection, with histologic evidence of decreased peri-infarct inflammation and fibrosis. ${ }^{12}$ We know, from our clinical experience, that neonate and infant hearts have greater potential for growth and regeneration. In many patients with pulmonary atresia and intact ventricular septum, the right ventricle (RV) grows after performing pulmonary valvotomy and/or RV overhaul procedures. However, this is not seen in school-age patients with pulmonary atresia and intact ventricular septum, even if the same procedures are performed. Our aim of regenerative therapy in patients with SV is simply to increase healthy myocardium, particularly in HLHS with RV-dominant anatomy. Human CDCs could be isolated from right atrial specimens, and a resident c-kit-expressing CPC subpopulation has been shown to be the most abundant and proliferative when grown from neonatal CDCs. This proliferative ability, however, declines with age. ${ }^{13}$ In addition, CDCs in neonatal hearts seem to have a greater regenerative ability than those derived from their adult counterparts. Although regenerative capacity seems to be superior in children compared with that of adult heart, ${ }^{14}$ there have only been a few notable contributions in children with CHD. Preclinical studies have been limited due to the lack of an adequate animal model that replicates all the salient features present in patients with CHD. One study in a neonatal lamb model of acute RV pressure overload demonstrated that intramyocardial injection of autologous umbilical cord blood (UCB) stem cells significantly improved load-independent indices of systolic and diastolic function compared with placebotreated lambs. ${ }^{15}$ Similarly, Hoashi and colleagues ${ }^{16}$ showed that in a rat model of RV pressure overload that transplantation of skeletal myoblast sheets improved diastolic function, reduced RV fibrosis, and increased capillary density compared with controls Experience in human pediatric patients has been limited to either case reports or small case series, with dilated cardiomyopathy the predominant disease type.

\section{CLINICAL TRIAL TO CHD: PHASE I TRANSCORONARY INFUSION OF CARDIAC PROGENITOR CELLS IN HYPOPLASTIC LEFT HEART SYNDROME (TICAP) AND PHASE II CARDIAC PROGENITOR CELL INFUSION TO TREAT UNIVENTRICULAR HEART DISEASE (PERSEUS)}

The first clinical trials of stem cell therapy in patients with SV physiology were conducted in Okayama University as phase I TICAP and as phase II PERSEUS trials. We designed a clinical trial to evaluate the safety and feasibility of transcoronary infusion of autologous CDCs for heart failure in children with HLHS as phase I TICAP. ${ }^{17,18}$ In our protocol, atrial tissue was obtained during bidirectional Glenn or Fontan operation to isolate CDCs. The cells were cultured to reach a cell number of 30,000 per kilogram of body weight and then infused into the coronary artery by cardiac catheterization 1 month after the surgical procedure. This protocol has the following advantages: (1) Cardiac progenitor cells are somatic stem cells with the greatest potential for regeneration of cardiac muscles among the stem cells that have been reported to date and are transplantable into the same individuals; (2) cardiac progenitor cells isolated from younger children are more abundant and have greater potential for myocardial regeneration than those from adults; (3) tissue 
specimens are obtained during cardiac surgery, so an additional invasive procedure such as bone marrow aspiration is not necessary; and (4) the number of progenitor cells can be standardized to a constant number on transplantation by implementing the in vitro culture process.

The TICAP trial was the first clinical trial to evaluate stem cell therapy in a population of infant patients with CHD. Although this was a small, phase I trial (7 treated and 7 control patients), the initial results at 18 months of follow-up not only showed safety and feasibility but also demonstrated significant improvements in systemic ventricular function, somatic growth, and QOL. The 3-year followup of these patients shows a persistence of these beneficial effects. ${ }^{18}$ The phase I controlled trial (TICAP) was started in 2011 and completed in January 2013.

Based on the encouraging results of the TICAP trial, we conducted the phase II study (PERSEUS) in April 2013. ${ }^{19}$ In the phase II study, we expanded the indication to patients with univentricular heart. To verify the efficacy, a total of 34 patients were randomly assigned to the treatment or control group in a 1:1 ratio. Cardiac ejection fraction was assessed by echocardiography, ventriculography, and cardiac magnetic resonance imaging at 3 and 12 months after treatment and compared with that of the control group. Using cardiac magnetic resonance with late gadolinium enhancement, we also assessed myocardial fibrosis, which was not investigated in the phase I study. The primary end point outcomes were to verify the efficacy of CDC infusion at 3-month follow up (study A). After primary end point analyses were finalized, late CDC infusion was conducted for the patients assigned as control group (study B). The secondary end point was to evaluate the cardiac function, heart failure status, somatic growth, and QOL, including parenting stress, after 12 months of observation. At primary end point analyses, cardiac magnetic resonance imaging showed absolute improvement in global ventricular ejection fraction, which was significantly greater in the CDC-treated group than in the control group $(6.4 \%$ vs $1.3 \%, P=.003)$. In study $\mathrm{B}$, late CDC infusion was carried out in all 17 patients, and significant improvement of cardiac function was observed compared with previous cell infusion $(38.8 \%$ vs $34.8 \%$, $P<.0001)$. Secondary outcomes that were analyzed revealed not only improvement of cardiac function compared with baseline $(41.4 \%$ vs $35.0 \%, P<.0001$, but also significant improvement of somatic growth and relief of heart failure status. It is well known that parents of children with CHD experience greater levels of distress compared with parents with healthy children. We found that QOL and parenting stress index were improved significantly after stem cell therapy. Moreover, even though there are a small number of patients, a reduction of cardiac fibrosis after CDC infusion was demonstrated. The results of the PERSEUS trial suggest robust evidence that intracoronary infusion of autologous CDCs have a positive effect for cardiac function. These beneficial effects of CDC implantation lead to a reduction of heart failure status, acceleration of somatic growth, which causes improvement of QOL, and relief of parental stress. The result of the PERSEUS trial has the potential to open a new avenue in the treatment of children with SV physiology. However, these clinical trials had the limitation that only a few study participants were enrolled as a long-term control arm because of ethical considerations. As such, we conducted a retrospective cohort study to evaluate the therapeutic efficacy of CDC infusion in patients with SV physiology at 2 years. ${ }^{20}$ In this study, intracoronary delivery or CDCs significantly improved ventricular function and reduced the incidences of late failure, adverse events, and unplanned catheter intervention in patients with single ventricles that underwent stage 2 or 3 palliation at 2 years of follow-up. We also reported that patients treated with CDCs had a lower hazard for the magnitude of treatment effects on adverse events and baseline cardiac function was an independent predictor of functional improvement after cell therapy.

There are several ongoing, stem cell-based cardiac regeneration trials in children. An industry-sponsored, multicenter, randomized phase III clinical trial for SV (APOLLON trial: NCT02781922) is ongoing at 3 children's hospitals, including Okayama university, to verify the risk/ benefit of intracoronary infusion of autologous CDCs in a large population. ${ }^{21}$ There are 2 clinical trials using autologous UCB stem cells for HLHS from The Mayo Clinic (NCT01883076) and Duke University (NCT01445041). Direct intramyocardial injection of UCB-derived mononuclear cells in an infant with HLHS has recently been published as a case report by the group at The Mayo Clinic. ${ }^{22}$ UCB was collected at the time of delivery and the mononuclear cell fraction was stored. At the stage 2 palliation, the cells were transplanted into the RV directly. Echocardiography at 3 months after transplantation revealed an improvement in RV ejection fraction of $35 \%$ to $50 \%$. Future studies and longer follow-up are required to evaluate the efficacy and safety of intramyocardial injection of UCB-derived stem cells in HLHS. Another clinical trial, The Allogeneic Human Mesenchymal Stem Cell Injection in Patients With Hypoplastic Left Heart Syndrome: An Open Label Pilot Study (ELPIS) trial, from the University of Maryland is ongoing and investigate of the safety and efficacy of intramyocardial injected allogeneic mesenchymal stem cells at the time of the stage II operation in patients with HLHS. Allogeneic stem cells are applied in children with HLHS to evaluate the safety and preliminary efficacy. In ELPIS trial, a total of 30 patients with HLHS will be enrolled in a staged enrollment process; 15 patients will eventually receive intramyocardial injection of the allogeneic mesenchymal stem cells, and 15 control patients will receive a placebo injection. 
Allogeneic CDC infusion has also begun in children with cardiomyopathy secondary to Duchene muscular dystrophy in the Heart Outcomes Prevention Evaluation (HOPE) trial. These challenging trials may be the pioneering work in the development of novel therapy against pediatric heart disease.

\section{MECHANISM OF STEM CELL THERAPY FOR HEART FAILURE}

CDCs have been shown to decrease scar mass, increase viable mass, and halt adverse remodeling in multiple animal and human studies. ${ }^{11,23}$ Accumulating evidence indicates that the benefits of CDCs are mediated by the secretion of exosomes. ${ }^{24}$ These natural nanoscale lipid bilayer vesicles mediate cell-cell communication, at least partially by transferring distinctive payloads of microRNAs and other noncoding RNAs. Transplanted stem cells repair damaged myocardium by releasing into the surrounding tissue, several factors such as cytokines and growth factors. Likewise, c-kit+CPCs generate vanishingly few mature cardiomyocytes but stimulate the proliferation of endogenous cells in the heart, which persists for at least 1 year postinjury. ${ }^{25}$ The latest reports related to mechanisms of action after stem cell therapy highlight the important role of exosomes. Exosomes released from human CDCs, or from CPCs not subjected to cardiosphere formation in vitro, were cardioprotective. ${ }^{26,27}$ They inhibited stressinduced cardiomyocyte apoptosis, induced cardiomyocyte proliferation, and stimulated angiogenesis compared with dermal fibroblast-derived exosome in vitro. Exosomes derived from CDC promote angiogenesis, cardiomyocyte survival, and an antifibrotic effect, which is mediated by micro RNA transfer. ${ }^{28}$ It is obvious that we have to continue to enhance our understanding of both cellular and molecular mechanisms of cardiac repair with stem cell therapy.

\section{CONCLUSIONS}

A wide range of stem cells have been identified and investigated in clinical trials with positive results. In the field of CHD, the results of the TICAP and PERSEUS trail are promising. However, stem cell therapy for pediatric heart failure is still at its beginning phase, and many more studies are needed to elucidate the mechanisms of action. Although there are many hurdles to overcome, the future outlook for cardiac regeneration in children seems bright. The positive results from the TICAP and PERSEUS trials are a clinical breakthrough for cardiac regeneration therapy in patients with $\mathrm{CHD}$, and we are very encouraged that the race has begun.

\section{Conflict of Interest Statement}

Authors have nothing to disclose with regard to commercial support.

\section{References}

1. Sano S, Huang SC, Kasahara S, Yoshizumi K, Kotani Y, Ishino K. Risk factors for mortality after the Norwood procedure using right ventricle to pulmonary artery shunt. Ann Thorac Surg. 2009;87:178-85.

2. Stout KK, Broberg CS, Book WM, Cecchin F, Chen JM, Dimopoulos K, et al. Chronic heart failure in congenital heart disease: a scientific statement from the American Heart Association. Circulation. 2016;133:770-801.

3. Rossano JW, Shaddy RE. Heart failure in children: etiology and treatment. J Pediatr. 2014;165:228-33.

4. Oh H, Ito H, Sano S. Challenges to success in heart failure: cardiac cell therapies in patients with heart diseases. J Cardiol. 2016;68:361-7.

5. Ptaszek LM, Mansour M, Ruskin JN, Chein KR. Towards regenerative therapy for cardiac disease. Lancet. 2012;379:933-42.

6. Fisher SA, Doree C, Mathur A, Martin-Rendon E. Meta-analysis of cell therapy trials for patients with heart failure. Circ Res. 2015;116:1361-77.

7. Beltrami AP, Barlucchi L, Torella D, Baker M, Limana F, Chimenti S, et al. Adult cardiac stem cells are multipotent and support myocardial regeneration. Cell. 2003;114:763-76

8. Chugh AR, Beache GM, Loughran JH, Mewton N, Elmore JB, Kajstura, et al. Administration of cardiac stem cells in patients with ischemic cardiomyopathy: the SCIPIO trial: surgical aspects and interim analysis of myocardial function and viability by magnetic resonance. Circulation. 2012;126:S54-64.

9. Malliaras K, Makkar RR, Smith RR, Cheng K, Wu E, Bonow RO, et al. Intracoronary cardiosphere-derived cells after myocardial infarction: evidence of therapeutic regeneration in the final 1-year results of the CADUCEUS trial (CArdiosphere-Derived aUtologous stem CElls to reverse ventricUlar dySfunction). J Am Coll Cardiol. 2014;63:110-2.

10. Kanazawa H, Tseliou E, Malliaras K, Yee K, Dawkins JF, De Couto G, et al. Cellular postconditioning: allogeneic cardiosphere-derived cells reduce infarct size and attenuate microvascular obstruction when administered after reperfusion in pigs with acute myocardial infarction. Circ Heart Fail. 2015;8:322-32.

11. Malliaras K, Li TS, Luthringer D, Terrovitis J, Cheng K, Chakravarty T, et al. Safety and efficacy of allogeneic cell therapy in infarcted rats transplanted with mismatched cardiosphere-derived cells. Circulation. 2012;125:100-12.

12. Sharma S, Mishra R, Bigham GE, Wehman B, Khan MM, Xu H, et al. A deep proteome analysis identifies the complete secretome as the functional unit of human cardiac progenitor cells. Circ Res. 2017;120:816-34.

13. Mishra R, Vijayan K, Colletti EJ, Harrington DA, Matthiesen TS, Simpson D, et al. Characterization and functionality of cardiac progenitor cells in congenital heart patients. Circulation. 2011;123:364-73.

14. Simpson DL, Mishra R, Sharma S, Goh SK, Deshmukh S, Kaushal S. A strong regenerative ability of cardiac stem cells derived from neonatal hearts. Circulation. 2012;126:S46-53.

15. Davies B, Elwood NJ, Li S, Cullinane F, Edwards GA, Newgreen DF, et al. Human cord blood stem cells enhance neonatal right ventricular function in an ovine model of right ventricular training. Ann Thorac Surg. 2010;89: 585-93.

16. Hoashi T, Matsumiya G, Miyagawa S, Ichikawa H, Ueno T, Ono M, et al. Skeletal myoblast sheet transplantation improves the diastolic function of a pressureoverloaded right heart. J Thorac Cardiovasc Surg. 2009;138:460-7.

17. Ishigami S, Ohtsuki S, Tarui S, Ousaka D, Eitoku T, Kondo M, et al. Intracoronary autologous cardiac progenitor cell transfer in patients with hypoplastic left heart syndrome: the TICAP prospective phase 1 controlled trial. Circ Res. 2015; 116:653-64.

18. Tarui S, Ishigami S, Ousaka D, Kasahara S, Ohtsuki S, Sano S, et al. Transcoronary infusion of cardiac progenitor cells in hypoplastic left heart syndrome: three-year follow-up of the transcoronary infusion of cardiac progenitor cells in patients with single-ventricle physiology (TICAP) trial. J Thorac Cardiovasc Surg. 2015;150:1198-207.

19. Ishigami S, Ohtsuki S, Eitoku T, Ousaka D, Kondo M, Kurita Y, et al. Intracoronary cardiac progenitor cells in single ventricle physiology: the PERSEUS randomized phase 2 trial. Circ Res. 2017;120:1162-73.

20. Sano T, Ousaka D, Goto T, Ishigami S, Hirai K, Kasahara S, et al. Impact of cardiac progenitor cells on heart failure and survival in single ventricle congenital heart disease. Circ Res. 2018;122:994-1005.

21. Oh H. Cell therapy trials in congenital heart disease. Circ Res. 2017;120: 1353-66.

22. Burkhart HM, Qureshi MY, Peral SC, O'Leary PW, Olson TM, Cetta F, et al. Regenerative therapy for hypoplastic left heart syndrome: first report of intraoperative intramyocardial injection of autologous umbilical-cord blood-derived cells. J Thorac Cardiovasc Surg. 2015;149:e35-7. 
23. Malliaras K, Smith RR, Kanazawa H, Yee K, Seinfeld J, Tseliou E, et al. Validation of contrast-enhanced magnetic resonance imaging to monitor regenerative efficacy after cell therapy in a porcine model of convalescent myocardial infarction. Circulation. 2013;128:2764-75.

24. Ibrahim AG, Cheng K, Marban E. Exosomes as critical agents of cardiac regeneration triggered by cell therapy. Stem Cell Rep. 2014;2: 606-19.

25. Tang XL, Li Q, Rokosh G, Sanganalmath SK, Chen N, Ou Q, et al. Longterm outcome of administration of c-kit (POS) cardiac progenitor cells after acute myocardial infarction: transplanted cells do not become cardiomyocytes, but structural and functional improvement and proliferation of endogenous cells persist for at least one year. Circ Res. 2016;118: 1091-105.

26. Timmers L, Lim SK, Arslan F, Armstrong JS, Hoefer IE, Doevendans PA, et al Reduction of myocardial infarct size by human mesenchymal stem cell conditioned medium. Stem Cell Res. 2007;1:129-37.

27. Mathivanan S, Ji H, Simpson RJ. Exosomes: extracellular organelles important in intercellular communication. J Proteomics. 2010;73:1907-20.

28. Gallet R, Dawkins J, Valle J, Simsolo E, de Couto G, Middleton R, et al. Exosomes secreted by cardiosphere-derived cells reduce scarring, attenuate adverse remodelling, and improve function in acute and chronic porcine myocardial infarction. Eur Heart J. 2017;38:201-11. 